\title{
Apresentação clínica da alergia ao leite de vaca com sintomatologia respiratória*
}

\author{
FÁBIO FERREIRA DE CARVALHO JUNIOR ${ }^{1}$
}

\begin{abstract}
Os alérgenos do leite de vaca são os primeiros antígenos a entrar em contato com a criança. A sintomatologia, em geral multissistêmica, pode estar relacionada ao trato gastrointestinal, à pele e, raramente, ao aparelho respiratório. Objetivo: Descrever algumas características clínicas e epidemiológicas de crianças com alergia ao leite de vaca com sintomas respiratórios. Casuística e método: Foram avaliadas retrospectivamente 17 crianças com acometimento do trato respiratório imediato à ingestão de leite de vaca que, com a exclusão deste tipo de alimento por quatro a seis semanas, se tornaram assintomáticas e, posteriormente, voltaram a apresentar sintomas respiratórios com a reintrodução, em ambiente hospitalar, do leite de vaca. Resultados: Não houve diferença quanto ao sexo e 14 das 17 crianças tinham antecedentes atópicos familiares. O tempo médio do aleitamento materno exclusivo foi de 2,9 meses e o do início dos sintomas, de 3,6 meses. Oito dos dez testes de hipersensibilidade cutânea imediata ao leite de vaca foram positivos. As manifestações clínicas foram: lactente chiador (nove), asma (cinco), otite de repetição (duas), deficiência seletiva de IgA associada com broncoespasmo (duas), rinoconjuntivite alérgica (uma). Conclusão: Em lactentes chiadores a alergia ao leite de vaca deve ser incluída no diagnóstico diferencial e em pacientes com antecedentes familiares atópicos deve ser estimulado o aleitamento materno exclusivo. Entretanto, o diagnóstico preciso é importante para evitar privações alimentares desnecessárias.
\end{abstract}

(J Pneumol 2000;27(1):17-24)

\section{Clinical presentation of cow milk allergy symptoms}

Cow milk allergens are the first antigens children have contact with. The symptoms, which are frequently multi-systemic, may be related to the gastrointestinal tract, to the skin and, more rarely, to the respiratory tract. Objective: To describe some clinic and epidemiological characteristics of children who have cow milk allergy and present respiratory symptoms.

Patients and method: This retrospective study included 17 children who presented respiratory problems immediately after ingesting cow milk, showed no symptoms as cow milk was excluded from their diets for a period of 4 to 6 weeks, and presented recurrent symptoms as cow milk was reintroduced into their diet in a hospital environment. Results: No difference was observed between genders. Family atopic antecedents were present in 14 of the 17 children. Mean exclusive breast-feeding period was 2.9 months and the onset of symptoms occurred at an average of 3.6 months. Eight of the ten tests conducted to evaluate immediate cutaneous hypersensitivity to cow milk were positive. Clinical manifestations observed were: wheezing infants (9), asthma (5), repetition otitis (2), selective IgA deficiency related to wheezing and allergic rhinoconjunctivitis (1). Conclusion: Regarding wheezing infants, cow milk allergy should be included as a differential diagnosis and exclusive breast-feeding should be stimulated in cases of atopic family antecedents. However, a precise diagnosis is vital to prevent unnecessary food deprivation.

* Trabalho realizado no setor de Imunologia Pediátrica da Santa Casa de São Paulo. Tese de Mestrado em Pediatria apresentada à Faculdade de Ciências Médicas da Santa Casa de São Paulo, em agosto de 1998, orientada pelo Prof. Dr. Celso Carlos de Campos Guerra.

1. Especialista em Pediatria, Alergia e Imunologia e Médico Assistente do Setor de Imunologia Pediátrica.
Endereço para correspondência - Rua Comendador Miguel Calfat, 183, apto. 21 B - 04537-080 - São Paulo, SP. Tel./Fax 571-3273; Email: ffcarvalho@sti.com.br

Recebido para publicação em 16/2/00. Reapresentado em 16/ 5/00. Aprovado, após revisão, em 20/5/00. 
Descritores - Hipersensibilidade ao leite. Substitutos do leite humano. Sinais e sintomas respiratórios. Doenças respiratórias.

Key words - Milk hipersensitivity. Milk substitutes. Respiratory signs and symptoms. Respiratory diseases.

\section{INTRODUÇÃO}

Dentro do caótico estudo das alergias alimentares, a alergia ao leite de vaca é o modelo de estudo, pois apresenta a maior incidência e uma sintomatologia bastante variável. Seu estudo é prejudicado porque, na prática clínica, muitas vezes, os pesquisadores dividem-se em incrédulos, que subestimam sintomas, ou aqueles que os hiperestimam, levando crianças ao uso de dietas e privações desnecessárias, com graves conseqüencias nutricionais e psicológicas. Neste contexto há necessidade de uma constante revisão sobre o assunto, tentando elucidar quadros clínicos e métodos diagnósticos, simplificando e direcionando seu diagnóstico.

O desenvolvimento da alergia ao leite de vaca seguiu em paralelo com o desenvolvimento das civilizações. As primeiras descrições da alergia ao leite de vaca datam das eras bíblicas. Há descrições de doenças alérgicas relacionadas a alimentos desde o início da história do conhecimento médico. Hipócrates (Grécia, IV a.C.), Galeno (131210 a.C.) e Titos Lucrécio (Roma, 1 a.C.) descreveram reações orgânicas relacionadas a alimentos ${ }^{(1)}$. Com a Revolução Industrial $e$ o trabalho da mulher houve a necessidade da introdução de substitutos artificiais para o leite materno ${ }^{(2)}$. O ressurgimento da doença ocorreu no início do século, com as primeiras descrições a partir de $1901^{(3)}$.

Os mitos, as verdades e inverdades e os conceitos populares fazem com que seja necessário que se tenham fixados conceitos básicos importantes ao entendimento das reações alérgicas alimentares. Define-se alergia alimentar ou hipersensibilidade alimentar como as reações adversas à ingestão de determinados alimentos, reprodutíveis, e em que são encontradas evidências de reações imunológicas anormais envolvidas na sintomatologia (através de anticorpos, linfócitos $\mathrm{T}$ ou ambos). Este conceito, amplo, atenta para outros mecanismos de hipersensibilidade, além do tipo I, envolvidos ${ }^{(4-8)}$.

O uso abusivo do leite de vaca como substituto do leite humano levou a aumento da incidência dessa doença. Hoje, esta incidência está situada entre 1,9 e 7,5\%. Há diferenças significativas entre os trabalhos, já que há grande variabilidade de critérios diagnósticos, desenhos do estudo e de população estudada (tanto geográfica, quanto numericamente). Em abordagens recentes, prospectivas e com uso de métodos diagnósticos adequados, a verdadeira incidência encontra-se entre 2 e $3 \%$. Se o diagnóstico é feito apenas pela história clínica, este é supervalo-
Siglas e abreviaturas utilizadas neste trabalho

OMA - Otite média aguda

RCA - Rinoconjuntivite alérgica

HLA - Antígenos de histocompatibilidade

rizado, uma vez que sintomas sugestivos estão presentes em 5 a $15 \%$ das crianças, mas somente em um terço destas a relação com o leite de vaca é comprovada(9-11).

A alergia ao leite de vaca é uma doença quase que exclusiva dos lactentes e da infância, raramente descrita na adolescência. É freqüentemente descrita nos primeiros dois a três meses de idade e quase sempre desaparece após o quarto ano de vida. Estudos mostram que, na mesma família, a alergia ao leite de vaca pode apresentar manifestações clínicas diferentes e que as crianças com esse tipo de alergia podem desenvolver outros processos alérgicos, como eczema e asma ${ }^{(6-8)}$.

\section{OBJETIVo}

O objetivo de nosso estudo é descrever, retrospectivamente, através de dados clínicos, epidemiológicos e exames laboratoriais de baixa complexidade, crianças acompanhadas em nosso ambulatório especializado com o diagnóstico de alergia ao leite de vaca exclusiva (sem outro desencadeante), com sintomatologia respiratória única, $e$ avaliar a sua evolução, após a exclusão do leite de vaca e substituição por leite de soja.

\section{CASUÍSTICA E MÉTODOS}

Nosso estudo foi realizado no Ambulatório de Imunologia do Departamento de Pediatria da Irmandade da Santa Casa de Misericórdia de São Paulo, no período entre agosto de 1991 e dezembro de 1997, e aprovado pelo Comitê de Ética desta instituição.

Foram admitidas no estudo crianças que se enquadrassem em parâmetros rigorosos ao diagnóstico da alergia ao leite de vaca, a seguir:

1) História clínica detalhada, realizada pelo autor, seguida de exame clínico rigoroso com avaliação antropométrica, excluindo-se outros diagnósticos diferenciais possiveis;

2) Dieta de exclusão por quatro a 12 semanas, em média de seis semanas;

3) Remissão clínica da sintomatologia em trato respiratório: prurido periocular, eritema, lacrimejamento e congestão nasal, prurido nasal e ocular, rinorréia, irritabilidade, otalgia ou otorréia persistente, dispnéia, tosse seca ou chiado;

4a) Reintrodução do antígeno, de forma aberta (a mãe conhecendo o conteúdo administrado) ou fechada (sem o 
conhecimento materno), sem uso de placebo, dependendo da situação, em ambiente hospitalar;

4b) Associação de mecanismo imunológico envolvido (testes cutâneos de hipersensibilidade) e melhora clínica importante, quando não foi realizada a reintrodução do antígeno, no momento inicial, sendo considerado o diagnóstico;

5) Reaparecimento da sintomatologia, com a provocação alimentar e sua remissão com a nova exclusão do antígeno agressor.

Foram excluídas crianças que apresentaram história clínica duvidosa, em que não exista correlação sensata $e$ consistente entre os sintomas e a ingestão do leite de vaca, bem como a associação dos sintomas com processos infecciosos (virais e bacterianos), processos febris $e$ vômitos persistentes aliados a perda de peso, presença de sintomatologia de trato gastrointestinal, pele, sistema nervoso ou sistema osteoarticular; presença de cardiopatias congênitas, suspeita de tuberculose pulmonar, corpo estranho em trato respiratório, além de malformações pulmonares; presença de testes cutâneos de hipersensibilidade imediata positivos (maiores que o controle positivo) para ácaros (poeira total, dermatophagoides sp., dermatophagoides pteronissimus), epitélio de animais (cão e gato), mofo (alternaria sp., cladosporium sp., penicillium sp.), lã e capim.

Foi realizada, em todas as crianças, dieta de exclusão das proteínas de leite de vaca por período de quatro a seis semanas, findo o qual a mãe era orientada a retornar ao ambulatório para reintrodução. Foi orientada a substituição do leite de vaca por leite de soja.

A provocação, realizada em ambiente hospitalar, consistiu no oferecimento à criança de quantidades de leite de vaca, em alíquota de $10 \mathrm{ml}$ por dia, por três dias e, no quarto dia, quantidade normal à ingestão habitual do menor. As mães também foram orientadas quanto à sintomatologia que em casa pudesse surgir e à procura imediata do serviço de saúde. Os pacientes foram reavaliados clinicamente imediatamente antes da exposição e após duas horas e sempre que necessário. Quando a sintomatologia respiratória, motivo da suspeita diagnóstica, recrudescesse, o teste era suspenso e considerado positivo. Esta padronização de exclusão e reintrodução do leite de vaca é utilizada em nosso Serviço desde 1991.

A cada seis meses, período que julgamos adequado à reintrodução, uma vez que não existem marcadores ou exames que nos indiquem esse tempo, as crianças foram submetidas a nova provocação, aberta e em ambiente hospitalar; caso a criança por si só, sem nosso consentimento, transgredisse a dieta, o resultado desta transgressão era considerado uma provocação. Se a provocação fosse considerada positiva (com retorno da sintomatologia anterior), a criança era mantida no estudo e, se a provoca- ção fosse negativa, a criança era considerada curada $e$ retirada do estudo.

Todos os exames laboratoriais foram realizados no Laboratório Central da Santa Casa de Misericórdia de São Paulo, segundo padronização própria. Os testes cutâneos de hipersensibilidade imediata ao leite de vaca foram realizados por puntura (prick test) com leitura imediata, fazendo-se inoculação no antebraço direito, no período da manhã e com leitura após 15 minutos, utilizando-se conjuntos de puntores plásticos para cada criança e, num mesmo paciente, puntores diferentes para cada alérgeno. Todos os extratos alergênicos tiveram a mesma procedência (Aristeg $\left.{ }^{\circledR}\right)$, padronizados em Ubt. Os alérgenos testados foram leite de vaca, leite de soja, carne de por$\mathrm{co}$, clara de ovo, amendoim, peixe, controle positivo e controle negativo. Foram realizados também testes cutâneos para os aeroalérgenos mais freqüentes em nosso meio, sendo considerada a sua positividade como critério de exclusão (poeira total, dermatophagoides sp., dermatophagoides pteronissimus, epitélio de cão, epitélio de gato, alternaria sp., cladosporium sp., penicillium sp., lã e capim). No atendimento inicial, eram solicitados os seguintes exames: hemograma completo, dosagem de imunoglobulinas séricas por imunodifusão radial e testes cutâneos de hipersensibilidade imediata para alimentos e aeroalérgenos (realizados em dez crianças).

A análise estatística dos resultados (em número total, absoluto e em percentagens), apresentados em valores médios e variação máxima e mínima, foi realizada pelo software Epi-Info 6.0, do Centers for Disease Control, de Atlanta, EUA. A comparação entre a época de início dos sintomas e o tempo de aleitamento materno foi realizada pelo teste $t$ de Student, admitindo-se como significativo um valor de $p>0,05$ ou $5 \%$ (12).

\section{RESULTADOS}

Foram atendidas 17 crianças que preencheram os critérios diagnósticos, todas acompanhadas por este autor. Todas as crianças incluídas e descritas tiveram sintomatologia respiratória melhorada com a exclusão do leite de vaca.

Das 17 crianças, nove $(52,9 \%)$ eram do sexo masculino e oito $(47,1 \%)$ do feminino. Quando do início do acompanhamento, tinham média de idade de 14,7 meses (com desvio de 8,6 meses, variando entre sete e 37 meses).

O início dos sintomas deu-se em média aos 3,6 meses, variando entre zero (logo após a ingestão de leite) e 12 meses de idade.

O tempo médio de aleitamento materno foi de 2,9 meses, variando entre zero (sem aleitamento materno) $e$ nove meses. 
TABELA 1

Comparação entre o tempo de aleitamento materno exclusivo e o início dos sintomas

\begin{tabular}{lcccc}
\hline & Média $(\mathbf{m})$ & Desvio padrão $(\mathbf{m})$ & Variação $(\mathbf{m})$ & $\boldsymbol{p}$ \\
\hline Aleitamento materno exclusivo & 2,9 & 2,94 & $0-9$ & 0,196870 \\
Início dos sintomas & 3,6 & 2,89 & $0-12$ & \\
\hline
\end{tabular}

$\mathrm{m}=$ meses

TABELA 2

Resumo dos resultados da avaliação das imunoglobulinas séricas $(\mathrm{mg} / \mathrm{dl})$, mostrando a média e a variação máxima e mínima

\begin{tabular}{lrr}
\hline & Média & Variação (mín-máx) \\
\hline $\lg A$ & 80,1 & $0,0-249,0$ \\
$\lg M$ & 146,1 & $58,0-236,0$ \\
$\lg G$ & 931,4 & $493,0-1.696,0$ \\
\hline
\end{tabular}

Onze $(64,7 \%)$ crianças iniciaram a sintomatologia em período menor que uma semana após o desmame, ou seja, logo após a administração de leite de vaca, duas $(11,8 \%)$, entre uma e quatro semanas, uma $(5,9 \%)$, entre cinco e 12 semanas e três $(17,6 \%)$, em período maior que 12 semanas.

A comparação entre a época de início dos sintomas e o tempo médio de aleitamento materno mostrou-se concordante, com $\mathrm{p}=0,196870$ (Tabela 1).

$\mathrm{O}$ antecedente atópico estava presente em 14 crianças $(82,4 \%)$.

Os valores de imunoglobulinas séricas (IgA, IgG e IgM), recuperados em 16 crianças, estão expressos na Tabela 2 , mas em duas foram encontrados valores compativeis com deficiência seletiva de IgA (2/16, ou $12,5 \%)$.

Os testes cutâneos de hipersensibilidade imediata, realizados em dez crianças, apresentaram positividade de $80,0 \%(8 / 10)$ para leite de vaca. Nenhuma criança nesta casuística apresentou positividade para leite de soja, sendo detectada em uma alergia a clara de ovo associada.

Todos os pacientes foram submetidos a rigorosa dieta de exclusão de leite de vaca e derivados. Em 14 crianças foi possível a realização da provocação. Nenhuma criança foi submetida a dupla provocação-exposição ou ao uso de placebo. Em uma criança com testes cutâneos de hipersensibilidade imediata positivos para clara de ovo, foi realizada dieta de exclusão e posterior provocação, sendo considerada negativa. Em três crianças não foi realizada a provocação alimentar, uma vez que a melhora com a exclusão do leite de vaca foi dramática e evidente; neste caso, entendemos não ser ética a nova provocação.

Os diagnósticos finais, descritos na Tabela 3, mostram cinco $(29,4 \%)$ diagnósticos de asma brônquica, nove $(53,0 \%)$ crianças com diagnóstico de lactente chiador, duas
TABELA 3

Diagnósticos finais das 17 crianças

\begin{tabular}{lrrr}
\hline \multicolumn{1}{c}{ Diagnóstico final } & \multicolumn{2}{c}{ Freqüência } & $\begin{array}{c}\text { Freqüência } \\
\text { acumulada }(\%)\end{array}$ \\
\cline { 2 - 3 } & $\mathbf{N}^{\mathbf{0}}$ & $\mathbf{\%}$ & \\
\hline Bebê chiador & 7 & 41,2 & 41,2 \\
Bebê chiador e deficiência de IgA & 2 & 11,8 & 53,0 \\
Asma brônquica & 5 & 29,4 & 82,4 \\
OMA repetição & 2 & 11,8 & 94,2 \\
RCA & 1 & 5,8 & 100,0 \\
Total & 17 & 100,0 & \\
\hline
\end{tabular}

OMA: otite média aguda; RCA: rinoconjuntivite alérgica

TABELA 4

Tempo de evolução e idade final dos pacientes do estudo

Evolução (M, mín-máx) Idade final (M, mín-máx)

$21,8(8,0-45,0) \quad 25,4(10,0-48,0)$

$M=$ média, mín = mínimo e máx = máximo

com otites de repetição (OMA), duas com deficiência seletiva de IgA associadas a chiado e uma criança com rinoconjuntivite alérgica (RCA). Duas crianças apresentaram mais de um diagnóstico. Em todas as crianças houve o acometimento do aparelho respiratório (alto ou baixo). Houve duas crianças com acometimento do sistema imune (deficiência seletiva de IgA - 12,5\%).

O leite de soja foi escolhido como substituto ao leite de vaca em todas as 17 crianças.

Todas as crianças foram acompanhadas por período médio de 21,8 meses, variando entre oito e 45 meses (Tabela 4). A cura (provocação alimentar negativa) deu-se em seis crianças, em média, aos 31,2 meses de idade (variando entre 19 e 41 meses) após acompanhamento médio de 25,7 meses (variando entre 12 e 38 meses). Nas crianças que ainda apresentavam a doença (11), ou seja, tinham provocação alimentar positiva, a média de idade ao final do acompanhamento foi de 25,4 meses (variando entre 10,0 e 48,0 meses) após acompanhamento médio de 21,8 meses (com variação entre oito $e$ 45 meses) (Tabela 5). 
TABELA 5

Idade final, variação da idade, tempo de acompanhamento e variação

\begin{tabular}{lcccr}
\hline & Idade final & Variação & Acompanhamento & Variação \\
\hline Com remissão $(\mathrm{n}=6)$ & $31,2 \mathrm{~m}$ & $19-41 \mathrm{~m}$ & $25,7 \mathrm{~m}$ & $18-38 \mathrm{~m}$ \\
Sem remissão $(\mathrm{n}=11)$ & $25,4 \mathrm{~m}$ & $10-48 \mathrm{~m}$ & $21,8 \mathrm{~m}$ & $8-45 \mathrm{~m}$ \\
\hline $\mathrm{m}=$ meses & & &
\end{tabular}

$\mathrm{m}=$ meses

\section{DISCUSSÃO}

A alergia alimentar e seu modelo, a alergia ao leite de vaca, têm importância inquestionável na prática pediátrica.

Inicialmente, contávamos com um número maior de crianças (24), mas com a aplicação de critérios diagnósticos restritos, esse número foi reduzido para 17 , demonstrando a fragilidade diagnóstica em sete crianças e a necessidade de revisão criteriosa caso a caso. Estes problemas, em escala muito maior, devem ser encontrados por muitos pediatras, pneumologistas e alergistas. Host, em 1994, afirmou que aproximadamente um terço dos casos sugestivos de alergia ao leite de vaca não são confirmados através de métodos adequados ${ }^{(9)}$. Em nosso estudo, $29,1 \%$ dos casos suspeitos não foram confirmados.

Neste grupo de sete crianças, o diagnóstico baseou-se na história clínica compatível e na melhora com dieta de exclusão, mas não foram realizadas provocações ou pesquisados parâmetros imunológicos. Outro motivo importante foi a associação do quadro respiratório com desencadeantes aeroalérgenos, comprovado com testes cutâneos positivos a estes, tornando insubsistente a relação entre a sintomatologia e a alergia alimentar. Nas crianças não submetidas aos testes cutâneos foram feitas a exclusão e a provocação com leite de vaca e derivados.

Este estudo visa descrever os achados em 17 pacientes com sintomatologia respiratória associada à ingestão de leite de vaca, cotejando com os dados pertinentes encontrados na literatura, comparando algumas de suas variáveis, tendo em mente suas próprias particularidades; nossos resultados serão avaliados coletivamente, sem a discriminação individual dos pacientes.

A maioria dos pacientes estudados é do sexo masculino, embora sem significância estatística. Homens e mulheres são igualmente afetados pela alergia ao leite de vaca e, apesar do evidente predomínio de história familiar de atopia em pacientes atópicos, nenhum fator genético foi, até o momento, identificado nesta doença. Existe associação íntima dos antígenos de histocompatibilidade (HLA) e a alergia; outros estudos promissores com o cromossomo 11q (braço longo do cromossomo 11) ainda têm muito a elucidar. Ainda não se conhecem, portanto, marcadores genéticos da atopia ${ }^{(13)}$.
O antecedente familiar atópico é característica marcante em nosso estudo: $82 \%$ das crianças com pai, mãe ou ambos atópicos. Jakobsson e Lindberg, em 1979, descreveram antecedente familiar de atopia em $70 \%$ de sua casuística ${ }^{(14)}$. Em clássico estudo de Bousquet e Kjellman, de 1986, foi descrito risco de desenvolvimento de atopia de 40 a $60 \%$ se ambos os pais são atópicos e de 20 a $40 \%$ se um dos pais é atópico ${ }^{(15)}$.

Os pacientes têm média de início da sintomatologia coincidente com a introdução do leite de vaca, sendo a imaturidade da barreira mucosa intestinal um fator de fundamental importância no desenvolvimento da doença. O desenvolvimento da alergia ao leite de vaca envolve possivelmente fatores genéticos e a exposição ambiental. A maturidade desenvolve-se com a idade e é manifesta pela habilidade de processamento do antígeno(11,16,17). Host et al., em 1995, mostraram que a diferença entre a data da primeira exposição ao leite de vaca $e$ o início da sintomatologia, na maioria das vezes, é menor que uma semana ${ }^{(10)}$.

Host et al. (1995) e Lovegroove et al. (1996) são unânimes em afirmar o importante papel do leite materno na prevenção de doenças atópicas e, em especial, a alergia ao leite de vaca ${ }^{(10,18)}$. Esteban, em 1992, relatou grupos de crianças com alergia ao leite de vaca, que, introduzido antes do primeiro mês de vida, provocou o desenvolvimento da sintomatologia dessa alergia a partir desse momento ${ }^{(19)}$.

A associação de alergia ao leite de vaca e deficiência seletiva de IgA já foi sugerida por vários autores ${ }^{(11,20,21)} e$ foi encontrada em nosso estudo em duas crianças. Os níveis de IgG, IgM e IgA na maioria das crianças encontram-se dentro da normalidade, ou seja, acima do percentil 2,5 da tabela proposta por Naspitz et al., em $1982^{(22)}$, para crianças brasileiras. Esses achados nos levam a pressupor que a IgA tem papel fundamental na passagem e processamento do antígeno na barreira gastrointestinal. Isso reforça a hipótese da imaturidade imunológica e da falta de habilidade do intestino em processar os antígenos, em indivíduos alérgicos ao leite de vaca.

Todas as crianças estudadas têm sintomatologia relacionada ao mecanismo de hipersensibilidade do tipo I de Gell e Coombs (de início imediato), o que torna os testes 
cutâneos de hipersensibilidade imediata importantes ao diagnóstico. Esse exame não foi realizado em sete crianças, pois, no início do estudo, acreditávamos que não seria de interesse diagnóstico e utilizávamos somente a exclusão-provocação, além de não dispormos, naquele momento, de extratos estáveis e padronizados.

Sampson, em 1983, descreveu a realização de 111 reintroduções fechadas, duplo-cegas e placebo-controladas em 26 crianças com dermatite atópica, que tinham pelo menos um teste cutâneo de hipersensibilidade imediata positivo ao leite de vaca. Houve somente $50 \%$ de concordância entre ambas, sugerindo que o teste cutâneo positivo associado à história familiar de atopia seria importante na seleção de pacientes para realização de provocação fechada e mostrando que o teste cutâneo poderia ser útil na escolha dos pacientes para realização de provocação $^{(23)}$.

Atkins et al., em 1985, descreveram forte correlação entre a presença de testes cutâneos para alérgenos alimentares e reações prévias do trato respiratório, além de história clínica suspeita. Posteriormente, os mesmos autores descreveram a correspondência da sintomatologia referida na história com os resultados dos testes cutâneos e a provocação alimentar, com os alimentos suspeitos. Tais trabalhos suportam o fato de nosso estudo utilizar os testes cutâneos de hipersensibilidade imediata ao leite de vaca como importante meio diagnóstico (24-26).

Uma revisão dos dados de Rasänen et al., publicados em 1992, mostra positividade dos testes cutâneos para leite de vaca em $81,8 \%$, muito semelhante aos resultados de nosso estudo. A associação dos testes cutâneos de hipersensibilidade imediata com a dieta de exclusão com provocação aberta tornou o diagnóstico bastante preciso. A melhora com a dieta de exclusão foi marcante em todas as crianças, não sendo necessária a provocação em três, que possuíam testes positivos ${ }^{(27)}$.

Ressaltamos que o diagnóstico da alergia ao leite de vaca não deve ser baseado exclusivamente nos testes cutâneos de hipersensibilidade e que este diagnóstico está relacionado à realização de provas de exclusão e provocação do alimento. Os testes cutâneos são exames que, quando positivos, sugerem, mas não confirmam o diagnóstico.

Hill e Hosking, em 1991, descreveram as dificuldades e a falta de praticidade do uso de provocações duplocegas e placebo-controladas em lactentes ${ }^{(28)}$. Por sua vez, Host e Halken, em 1990(29), e Host, em 1994(9), observaram boa correlação entre resultados de estudos abertos em ambiente hospitalar e a exposição duplo-cega placebo-controlada. A exposição duplo-cega serviria para excluir a influência psicológica, de menor importância em crianças $^{(30)}$.

Hill e Hosking, em 1995, descreveram que, na prática clínica, utilizam exposição aberta associada a exposição duplo-cega placebo-controlada ou a demonstração de reatividade cutânea nos testes de hipersensibilidade imediata para extrato de leite de vaca(11).

Em nossa casuística foi utilizado o método aberto de reintrodução do leite de vaca, sem uso de placebo, método este que está de acordo com a literatura.

O leite de soja é um substituto barato, de sabor palatável, e lactentes têm crescimento normal com seu uso e não interfere na indução da tolerância ${ }^{(31,32)}$. Há grande controvérsia sobre a alergenicidade da soja ${ }^{(33)}$, variando entre 5 e 80\%. Esta controvérsia levou o Comitê de Nutrição de Academia Americana de Pediatria, já em $1983^{(34)}$, e a Sociedade Européia de Alergia Pediátrica e Imunologia Clínica, em $1993^{(35)}$, a não recomendarem o leite de soja como substituto ao leite de vaca. Outros importantes autores o descrevem como opção em crianças com alergia mediada por $\mathrm{IgE}^{(33)}$ ou em quadros de pele ou pulmonares ${ }^{(36)}$. Na prática, substitui-se o leite de vaca por leite de soja, devido à facilidade de adquiri-lo e pelo baixo custo(37).

Das 17 crianças deste estudo, em 14 foi realizada provocação, aberta e em ambiente hospitalar, sendo considerada positiva (aparecimento de sibilância ou rinorréia abundante durante o período de observação de até duas horas após a provocação) em 12 crianças. Em duas crianças, que apresentavam otite média de repetição, a sintomatologia consistiu de quadro clínico compativel (dor no local, irritação, febre e alterações na membrana timpânica) até 48 horas após a reexposição. Em três crianças que tiveram importante e dramática melhora do seu quadro clínico após a exclusão do leite de vaca, associou-se a presença de testes cutâneos de hipersensibilidade imediata para leite de vaca para a realização do diagnóstico. Trata-se de uma descrição dos pacientes e naquele momento entendemos não ser necessária a reintrodução. Esta reintrodução foi realizada posteriormente, de forma espontânea, pelas mães, e confirmou o diagnóstico, já que houve o retorno da sintomatologia.

O padrão de sintomatologia referido na literatura mundial demonstra o predomínio do envolvimento da pele $e$ do trato gastrointestinal. $\mathrm{O}$ envolvimento do aparelho respiratório é muito menos freqüente, variando entre $2 e$ $8,5 \%$ em asmáticos ${ }^{(38-41)}$, sendo raro como acometimento isolado ${ }^{(6-8,42)}$.

As reações imunológicas do tipo I, já descritas, não são freqüentemente relacionadas à sintomatologia respiratória na literatura, mas, em nosso estudo, as crianças submetidas à reexposição apresentaram quadro respiratório, a maioria, principalmente na primeira hora após a provocação.

A sintomatologia respiratória alta ou baixa tem sido descrita como conseqüência de várias provocações alimentares. Os alérgenos alimentares são capazes, em minutos ou em até duas horas, de induzir uma gama diversa de 
sintomas, desde típicos de rinoconjuntivite alérgica, sibilância, até alterações espirométricas com queda da capacidade vital forçada, do volume expiratório forçado no primeiro segundo e dos fluxos expiratórios máximo e mínimo durante provocação duplo-cega placebo-controlada ${ }^{(43-45)}$.

James et al., em 1994, descreveram 320 pacientes com dermatite atópica, 2/3 portadores de alergia alimentar. Em um ano de avaliação, metade apresentou asma ou rinite como sintomatologia e 59\% desenvolveram sintomas durante a provocação fechada e duplo-cega. Esses sintomas incluíam congestão nasal, rinorréia, prurido nasal e obstrução nasal, além de tosse e disfonia. O acometimento das vias aéreas inferiores determinou o aparecimento de dispnéia, tosse seca e chiado em $17 \%$ das crianças. A avaliação espirométrica em 88 crianças mostrou significante redução do $\mathrm{FEV}_{1}$ em 11 delas. Em somente seis crianças houve importante diminuição da fração ex-

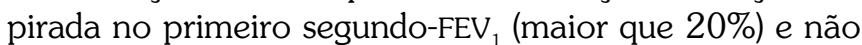
houve fase tardia de resposta asmática em nenhum paciente após dez horas ${ }^{(44)}$.

Sampson, em 1995, descreve desafios alimentares duplo-cegos e placebo-controlados em 17 asmáticos com documentada alergia alimentar, monitorados através de avaliação espirométrica e broncoprovocações com metacolina antes e após quatro horas da provocação alimentar. Em 12 pacientes as reações foram consideradas positivas, com nove manifestações de sintomas pulmonares (cinco crianças com tosse, duas com chiado e uma com tosse e chiado). Neste grupo, seis crianças mostraram aumento da concentração de metacolina necessária para diminuir em $20 \%$ o $\mathrm{FEV}_{1}$ (PD20) (somente uma não apresentava chiado). Em quatro dos seis pacientes houve diminuição do $\mathrm{FEV}_{1}$ maior que $10 \%$. Conclui, então, que durante a provocação pode haver aumento da reatividade das vias aéreas em pacientes asmáticos e ocorrer, inclusive, sem demonstrar mudança significativa no $\mathrm{FEV}_{1}$ durante o desafio ${ }^{(45)}$.

Em nosso estudo descrevemos predomínio do acometimento do trato respiratório, que pode ser explicado pela triagem própria deste ambulatório, que tem por norma encaminhar todos os casos de sintomatologia gastrointestinal ao Ambulatório de Gastroenterologia Pediátrica e os casos de pele ao Ambulatório de Dermatologia desta mesma instituição. Chamam atenção os casos de asma brônquica, otites de repetição e os lactentes chiadores, que evoluíram para importante melhora com a exclusão do leite de vaca e dos derivados lácteos. Ainda é importante o fato de o acometimento do trato respiratório ser decorrente principalmente do mecanismo de hipersensibilidade do tipo I de Gell e Coombs, identificadas neste estudo. Houve a associação entre acometimento do trato respiratório (lactente chiador) com alteração no sistema imune, especificamente com deficiência de IgA. Outras manifestações não foram encontradas em nosso estudo. Ressalte-se a importância do diagnóstico diferencial com refluxo gastroesofágico, uma vez que sua associação com alergia ao leite de vaca é situada entre 16 e 41,8\%. Nosso estudo preconizou atitudes mais conservadoras, fazendo esta diferenciação através da história e do quadro clínico (vômitos persistentes, emagrecimento, chiado persistente após a exclusão do leite de vaca, por exemplo) $e$ também a partir da importante melhora clínica com a exclusão dos derivados lácteos, assim como Staiano et al., em 1995(46).

Há controvérsias quanto à idade em que se adquire a tolerância ao leite de vaca, havendo remissão dos sintomas. Jakobssen e Lindberg, em 1979(14), estudando 20 crianças, encontraram $60 \%$ de tolerância aos dois anos. Bock, em 1987(47), em 25 crianças, encontrou $84 \%$ de remissão aos três anos e Host e Halken, em 1990(29), em 39 crianças, encontraram $87 \%$ de remissão aos três anos. Há diferenças quanto à associação de aeroalérgenos ou outras alergias alimentares associadas. Outros estudos mostram remissão variando entre $33 \%$ em seguimento de quatro anos até $100 \%$ em dois anos. Em nosso estudo, seis crianças foram consideradas curadas $(6 / 17$ $35,3 \%)$, a maioria destas $(4 / 6-66,7 \%)$ até a idade de 34 meses e todas $(6 / 6-100 \%)$ melhoraram até os quatro anos de idade. Talvez a não melhora, ou seja, o reaparecimento dos sintomas com a reintrodução do leite de vaca, esteja relacionado a melhora mais tardia das crianças com sintomatologia respiratória única. Ao compararmos com os resultados da literatura, vemos que há alguma coincidência na época de remissão, quando esta ocorreu, com consenso ao redor do quarto ano, porém não há predominância de sintomatologia respiratória nestes grupos.

A evolução para a cura parece ser inexorável, embora 11 crianças de faixa etária e acompanhamento semelhantes não desenvolvessem tolerância ao leite de vaca após sucessivas provocações. A alergia ao leite de vaca traz transtornos à criança e seu crescimento, mas tem evolução benigna na grande maioria das vezes.

Concluímos, salientando a necessidade do estímulo ao aleitamento materno exclusivo, principalmente em crianças com antecedente familiar atópico presente, bem como a de incluir a alergia ao leite de vaca como diagnóstico diferencial em lactentes chiadores, mesmo sem a concomitância de quadros gastrointestinais ou de pele. $\mathrm{O}$ diagnóstico preciso de alergia ao leite de vaca deve ser realizado através de métodos adequados, como a dieta de exclusão com provocação, ou associação de alguns exames, uma vez que não existe um exame laboratorial que dê o diagnóstico de alergia ao leite de vaca e, sim, exames laboratoriais que inferem a doença, $e$, por fim, ressaltar que o diagnóstico errado pode ter conseqüências físico-psicossociais importantes. 


\section{REFERÊNCIAS}

1. Freir S, Kletter B. Milk allergy in infants and young children. Clin Pediatr (Phila) 1970;9:449-554.

2. Goode WJ. Revolução mundial e padrões de família. São Paulo: Edusp, 1969;26-37.

3. Hamburger F. Biologisches uber die eiwess-korper der kuhmich und uber sanglings-ernahrung. Wien Klin Wochenschr 1901;14:1202.

4. Fergusson A. Definitions and diagnosis of food intolerance and food allergy: consensus and controversy. J Pediatr 1992;121:S7-S11.

5. Metcalfe DD, Sampson HA, Simon RA, eds. Food allergy: Adverse reactions to foods and food additives. Boston: Blackwell Scientific Publications, 1997.

6. Sampson HA. Food allergy. Part 1: Immunopathogenesis and clinical disorders. J Allergy Clin Immunol 1999;103:717-728.

7. Sampson HA. Food allergy. Part 2: Diagnosis and management. J Allergy Clin Immunol 1999;103:981-989.

8. Esteban MM, Calvo JB, Aragonés AM, Falcó SN, Plaza Martin AM. Adverse reactions to cow's milk proteins. Allergol Immunopathol (Madr) 1999;26:171-194.

9. Host A. Cow's milk protein allergy and intolerance in infancy: some clinical epidemiological and immunological aspects. Pediatr Allergy Immunol 1994;5(Suppl 5):1-36.

10. Host A, Jacobsen MP, Halken S, Holmenlund D. The natural history of cow's milk protein allergy intolerance. Eur J Clin Nutr 1995;49 (Suppl 1):513-519.

11. Hill DJ, Hosking CS. The cow milk allergy complex: overlapping disease profiles in infancy. Eur J Clin Nutr 1995;49(Suppl 1):S1-S12.

12. Dean AG, Dean JA, Coulombier D. Epi Info, Version 6: a word processing, database, and statistics program for epidemiology on microcomputers. Centers for Disease Control and Prevention. Atlanta, Georgia, USA, 1994.

13. Bousquet J, Michel FB. Predictors of risk of allergy. In: Week AL, Sampson HA, eds. Intestinal immunology and food allergy. New York: Raven Press, 1995;93-105 (Nestlé Nutrition Workshop Series).

14. Jakobsson I, Lindberg TA. A prospective study of cow's milk protein intolerance in Swedish infants. Acta Pediatr Scand 1979;68:853-859.

15. Bousquet J, Kjellman NIM. Preventive value of tests in childhood allergy. J Allergy Clin Immunol 1986;78:1019-1022.

16. Sanderson IR, Walker WA. Uptake and transport of macromolecules by the intestine. In: Week AL, Sampson HA, eds. Intestinal immunology and food allergy. New York: Raven Press, 1995;19-36 (Nestlé Nutritional Workshop Series).

17. Brandtzaeg P, Thrane PS. Ontogeny of the mucosal immune system. In: Week AL, Sampson HA, eds. Intestinal immunology and food allergy. New York: Raven Press, 1995;1-17 (Nestlé Nutritional Workshop Series).

18. Lovegroove JA, Morgan JB, Hampton SM. Dietary factors influency levels of food antibodies and antigens in breast milk. Acta Paediatr 1996;85:778-784.

19. Esteban MM. Adverse food reactions in childrood: concept, importance and present problems. J Pediatr 1992;121:S1-S3.

20. Hill DJ. Cow's milk allergy in infants: some clinical and immunologic features. Ann Allergy 1996;57:225-228.

21. Walker-Smith JA. Cow milk sensitive enteropathy: predisposing factors and treatment. J Pediatr 1992;121:S111-S115.

22. Naspitz CK, Solé D, Carneiro-Sampaio MMS, Gonzales CH. Niveis de imunoglobulinas séricas em adultos e crianças normais brasileiros nos diferentes períodos etários. J Pediatr (RJ) 1982;52:121-126.

23. Sampson HA. Role of immediate food hypersensitivity in the pathogenesis of atopic dermatitis. J Allergy Clin Immunol 1983;71:473480.

24. Atkins FM, Steinberg MS, Metcalfe DD. Evaluation of immediate adverse reactions to food in adult patients: correlation of demographic, laboratory and prick skin test data with response to controlled oral food challenge. J Allergy Clin Immunol 1985;75:348-355.
25. Atkins FM, Steinberg MS, Metcalfe DD. Evaluation of imediate adverse reactions to food in adult patients: a detailed analysis of reaction patterns during oral food challenge. J Allergy Clin Immunol 1985;75: 336-363.

26. Iacono G, Carroccio A, Catavio F, et al. Gastroesophageal reflux and cow's milk allergy in infants: a prospective study. J Allergy Clin Immunol 1996;97:822-827.

27. Rasänen L, Letho M, Reunala T. Diagnostic value of skin and laboratory tests in cow's milk allergy intolerance. Clin Exp Allergy 1992;22: 385-390.

28. Hill DJ, Hosking CS. Some limitations of double blind placebo controlled food challenges in young children [Letter to editor]. J Allergy Clin Immunol 1991;87:137.

29. Host A, Halken S. A prospective study of cow's milk allergy in Danish infants during the first three years of life. Allergy 1990;45:227-232.

30. Pastorello EA, Stochi L, Pravettoni V, et al. Role of the elimination diet in adults with food allergy. J Allergy Clin Immunol 1989;84:475483.

31. Werwimp JJM, Bindels JG, Barents M, Heymans MSA. Symptomatology and growth in infants with cow's milk protein intolerance using two different whey-protein hydrolysate based formulas in primary health care setting. Eur J Clin Nutr 1995;49:S39-S43.

32. Galli F, Chini L, Paone F, et al. Comparazione clinica di differenti formule di latte sostitutivo in bambini con allergia alle proteine del latte vaccino. Minerva Pediatr 1996;48:71-77.

33. Businco L, Bruno G, Giampietro PG, Cantani A. Allergenicity and nutritional adequacy of soy protein formula. J Pediatr 1992;121:S21S28.

34. American Academy of Pediatrics. Committee on Nutrition - Soy-Protein Formulas: Recommendations for use in infant feeding. Pediatrics 1983;72:259-362.

35. European Society of Pediatric Allergy and Clinical Immunology (Espaci) position paper: Hydrolysed cow's milk formulae: allergenicity and use in treatment and prevention. Pediatr Allergy Immunol 1993;1: 101-111.

36. Dean TP. Cow's milk allergy: therapeutic options and immunological aspects. Eur J Clin Nutr 1995;4:S19-S25.

37. McDonald A. Which formula in cow's milk protein intolerance? The dietitian's dilemma. Eur J Clin Nutr 1995;49:S56-S63.

38. Oehling A, Cagnani CEB. Food allergy and child asthma. Allergol Immunopathol (Madr) 1980;8:7-14.

39. Onorato J, Merland N, Terral C, Michel FB, Bousquet J. Placebo double blind food challenge in asthma. J Allergy Clin Immunol 1986;78: 1139-1146

40. Novembre E, De Martino M, Vierucci A. Foods and respiratory allergy. J Allergy Clin Immunol 1988;81:1059-1065.

41. Bock SA. Respiratory reactions induced by food challenges in children with pulmonary disease. J Pediatr Allergy Immunol 192;3:188-194.

42. Levy Y, Kornbroth B, Oferi I, Garty BZ, Danon YL. Food allergy in infants and children: clinical evaluation and management. Isr J Med Sci 1994;30:873-879.

43. James JM, Sampson HA. Immunologic changes associated with the development of tolerance in children with cow milk allergy. J Pediatr 1992;121:S71-S77.

44. James JM, Bernhisel-Broadbent J, Sampson HA. Respiratory reactions provoked by DBFC in children. Am J Respir Crit Care 1994; 149:59-64.

45. Sampson HA. Nonintestinal manifestations of food hypersensitivity. In: Week AL, Sampson HA, eds. Intestinal immunology and food allergy. New York: Raven Press, 1995;119-129.

46. Staiano A, Troncone R, Simeone D, et al. Differentiation of cow's milk intolerance and gastroesophageal reflux. Arch Dis Child 1995;73:439442.

47. Bock SA. Prospective appraisal of complaints of adverse reactions of food in children during the first 3 years of life. Pediatrics 1987;79: 683-688. 